\title{
A ECONOMIA POPULAR E SOLIDÁRIA SOB A REPRESENTAÇÃO SOCIAL DAS MULHERES TRABALHADORAS DA COMUNIDADE QUILOMBOLA DE LAGOA GRANDE - FEIRA DE SANTANA - BA ${ }^{1}$
}

\author{
Jose Raimundo Oliveira Lima \\ Elianne Paraiso de Queiroz ${ }^{3}$ \\ Juliana de Freitas Silva ${ }^{4}$
}

\begin{abstract}
Resumo
Este trabalho apresenta ações de pesquisa realizada com um grupo produtivo acompanhado pela Incubadora de Economia Popular e Solidária da Universidade Estadual de Feira de Santana IEPS/UEFS. Tendo como objetivos: identificar as representações sociais do grupo Sabores do Quilombo sobre Economia Popular e Solidária; analisar o processo de incubação e, identificar as demandas formativas do grupo para a Incubadora. As atividades realizadas ao longo da pesquisa garantiram um diálogo com o saber popular e discussões sobre conflitos e relações grupais, através de um grupo psicoeducativo. Como resultados da pesquisa, ainda que parciais, pois o processo encontrase em andamento, inferimos que as trabalhadoras desenvolvem, de forma orgânica, elementos da economia popular e solidária, ainda que estes não estejam fixados ou sobre seus domínios conceituais.
\end{abstract}

Palavras-chave: Economia popular e solidária. Mulheres trabalhadoras quilombolas. Representações sociais.

\section{INTRODUÇÃO}

Experiências de trabalhos associados ou cooperados vêm crescendo ultimamente e construindo um movimento denominado de economia popular e solidária. O trabalho tem o objetivo de apresentar ações de pesquisa configurada como atividades educativas desenvolvidas com o grupo produtivo que está em processo de incubação pela Incubadora de Iniciativa de Economia Popular e Solidária da Universidade Estadual de Feira de Santana IEPS/UEFS.

No primeiro momento, vamos conceituar economia popular e solidária, em seguida, apresentaremos a IEPS/UEFS e a atividade desenvolvida com um grupo produtivo

\footnotetext{
${ }^{1}$ Apoio financeiro: Pró-reitoria de Extensão da UEFS (Bolsa de extensão).Pró-reitoria de Pesquisa da UEFS (Bolsa de pesquisa).

${ }^{2}$ Professor Adjunto do Curso de Economia da UEFS. Coordenador da IEPS-UEFS. Economista (UEFS). Mestre Gestão Integrada de Organizações (UNEB). Doutor em Educação e Contemporaneidade (UNEB). zeraimundo@uefs.br.

${ }^{3}$ Graduanda em Psicologia na Universidade Estadual de Feira de Santana. Bolsista de Extensão da Incubadora de Iniciativas da Economia Popular e Solidária da Universidade Estadual de Feira de Santana - Bahia. elianneparaiso@gmail.com.

${ }^{4}$ Graduanda em Ciências Econômicas na Universidade Estadual de Feira de Santana. Bolsista de Iniciação Científica da Incubadora de Iniciativas da Economia Popular e Solidária da Universidade Estadual de Feira de Santana - Bahia.julysofia.freitas@gmail.com.
} 
acompanhado pelo programa, a partir da explanação dos objetivos, metodologia, resultado e análise de resultados. Por fim, teremos as considerações finais.

\section{METODOLOGIA}

A metodologia deste trabalho compreende uma parte teórica sobre a metodologia trabalhada, bem como o instrumento de oficina praticada como ação da pesquisa.

A pesquisa-ação, enquanto método de pesquisa adotado pela IEPS/UEFS, afirma o caráter político de fazer ciência, uma vez que os envolvidos, universidade e comunidade, são colocados como sujeitos do processo de pesquisa e a sua realidade é o objeto da pesquisa, há uma relação de reciprocidade entre o saber popular e o científico.

[...] deste modo, fazendo pesquisa, educo e estou me educando com os grupos populares. Voltando à área para pôr em prática os resultados da pesquisa não estou somente educando ou sendo educado: estou pesquisando outra vez. No sentido aqui descrito pesquisar e educar se identificam em um permanente e dinâmico movimento (FREIRE, 1983, p.36).

As contribuições do pensamento de Freire (1983) para orientar o processo de incubação são de fundamental importância, pois reafirma o compromisso da ciência de servir à sociedade. Assim, os resultados obtidos durante o processo de incubação corroboram a afirmativa de Freire, ação-reação-ação e, nessa dialética, os sujeitos vão se tornando mais conscientes da sua própria realidade.

\footnotetext{
Este conhecimento, folclore ou sabedoria popular, não é codificado segundo os padrões de forma dominante e, por esta razão, é menosprezado como se não tivesse o direito de articular-se e expressar-se em seus próprios termos. Mas este conhecimento popular também possui sua própria racionalidade e sua própria estrutura de causalidade, isto é, pode-se demonstrar que tem mérito e validade científica per se (BORDA, 1983, p.45).
}

Nesses termos, optar por um método de pesquisa alternativo é desafiar a própria lógica hegemônica e ocidental de fazer ciência, e esta pesquisa participante que é a pesquisa da ação, protagoniza experiências, especialmente, das "populações que correspondem operários, camponeses, agricultores e índios” (BORDA, 1983, p.43). Acrescentamos, também, populações negras e quilombolas, é essa ciência popular que permeia a base da construção do conhecimento que a IEPS-UEFS defende e constrói diariamente. 


\section{OFICINA: UMA ATIVIDADE METODOLÓGICA DE INCUBAÇÃO}

O grupo do Projeto Cantina Solidária III estava para completar dois anos em processo de incubação quando esta ação foi desenvolvida, e como a Incubadora atua de maneira sistêmica, em que uma oficina demanda outra através das falas do grupo, é importante saber como as mulheres em processo de incubação descrevem a Economia Popular e Solidária e quais são os elementos que ainda precisam ser trabalhados. A IEPS/UEFS têm reuniões ordinárias, aberta aos grupos e visitantes, para garantir essa sistematização.

Decisões de datas para encontros com o grupo, intervenção dos bolsistas, datas para participação em eventos, discussão para resolução de problemas. [...] visita a outros grupos, participação em eventos e etc." (MOURA e LIMA, 2015, p.3, no prelo).

Esta atividade em questão faz parte de três oficinas construídas de maneira correlacionada. Entendendo que autogestão faz parte da história dos quilombos no Brasil, as três etapas foram elaboradas para identificar se o grupo do Projeto Cantina Solidária III associava a autogestão defendida pela Economia Popular e Solidária com sua própria história enquanto quilombola para um fortalecimento da prática autogestionária.

Segundo Clóvis Moura (1987), à medida que os quilombos cresciam, era pensado, internamente, modos de organização; o que inclui formas de governo, propriedade e economia. Esta economia, de acordo com o mesmo autor, se constituiu em oposição ao sistema de sesmarias, possuía uma cultura da terra introduzida pelos próprios habitantes e tinha a presença da solidariedade e da cooperação, desde o início dos quilombos, além disso, o autor ainda apresenta ideias de Waldemar de Almeida, que indica que o trabalho nos quilombos eram comunitários, nos quais os quilombolas se dividiam em grupos ou setores de acordo com sua especialidade (MOURA, 1987). Com o grupo Sabores do Quilombo ocorreu o mesmo: cada uma das trabalhadoras escolheu sua função a partir de afinidades.

As contribuições de Clóvis Moura apontam alguns dos princípios da Economia Popular e Solidária propostos por Paul Singer (2002) e defendidos pela IEPS/UEFS, como a solidariedade e cooperação. $\mathrm{O}$ fato da economia dos quilombos antigos se opor ao estabelecido na época e formular uma organização produtiva de maneira interna e coletiva, também se assemelha com a história da Economia Popular e Solidária, e são fatores importantes para o estabelecimento de uma prática autogestionária, já vivida pelo grupo 
produtivo e que sempre está em construção. Isso porque, segundo Paul Singer $(2005$, apud CASTANHEIRA \& PEREIRA, 2008) para a prática da autogestão, é necessária uma reeducação coletiva, e isso exige prática: é praticando a autogestão que se aprende a trabalhar de maneira autogestionária.

\begin{abstract}
O exercício da economia solidária exige que as pessoas formadas no sistema capitalista passem por um processo de reeducação coletiva, em que todos vivenciem em conjunto a transição da forma competitiva à forma cooperativa de organização. Um indivíduo agindo sozinho de modo cooperativo, em uma sociedade na qual predomina a competição, acaba sendo 'esmagado' economicamente. Da mesma maneira, um indivíduo que age competitivamente, onde predomina a economia solidária, passa a ser visto como egoísta e desleal pelos demais, sendo excluído de seu meio (CASTANHEIRA \& PEREIRA, 2008)
\end{abstract}

A primeira oficina teve como tema "O QUE É QUILOMBO/SER QUILOMBOLA", a segunda teve "ECONOMIA POPULAR E SOLIDÁRIA" e a terceira teve "AUTOGESTÃO" como norteador da discussão. As três oficinas tiveram a mesma metodologia, apenas o método da terceira etapa foi diferente e ainda não tinha sido realizada, não sendo possível a apresentação do trabalho completo.

A oficina teve como objetivo geral identificar as representações sociais do grupo Sabores do Quilombo sobre Economia Popular e Solidária, e como objetivos específicos analisar o processo de incubação e identificar as demandas formativas do grupo para a Incubadora.

De um modo geral, a realidade de comunidades é apresentada através das representações sociais, elas a constroem e são definidas como:

[...] um fenômeno que se refere a um conjunto de regularidades empíricas compreendendo as ideias, os valores e as práticas de comunidades humanas sobre objetos sociais específicos, bem como sobre os processos sociais e comunicativos que os produzem e reproduzem (JOVCHELOVICTH, 2008, p.87).

Ou seja, é através das representações sociais que uma comunidade explica e conceitua o mundo e foi neste conhecimento que a oficina teve como foco. Pensando nisso, a metodologia foi de grupo psicoeducativo com construção de quadro sobre Economia Popular e Solidária com as palavras das mulheres que formam o grupo, haja vista que o grupo advém de uma mesma comunidade. Como aponta Bazon (1997), grupo psicoeducativo permite 
trabalhar com saberes populares, com uma atenção aos sujeitos, as suas subjetividades e relações grupais, haja vista que:

\begin{abstract}
A nível conceitual, o modelo psicoeducativo fundamenta-se em dois postulados de base, a partir do qual decorre as concepções de meio de intervenção e de ação educativa: a) A visão de Ser Humano e b) O potencial educacional do cotidiano compartilhado" no dia-a-dia dos meios de intervenção" (BAZON, 1997, p.32)
\end{abstract}

Elaborada para que todas as mulheres do grupo falassem, o método escolhido foi o de cada pessoa apresentar uma palavra a ser destrinchada em seguida, com discussão coletiva. Inicialmente foi pedido para que cada uma dissesse qual palavra vinha na cabeça ao ouvir "Economia Popular e Solidária", e depois cada uma teve que destrinchar a palavra e explicar qual a relação desta com o tema da oficina. Em um terceiro momento, foi permitido trazer mais contribuições para as palavras de todas, ficando no mural apenas os termos consensuados. A oficina foi finalizada com uma avaliação geral sobre a condução, as discussões e afetamentos causados pela conversa.

\title{
ECONOMIA POPULAR E SOLIDÁRIA
}

A Economia Popular e Solidária (EPS) se opõe ao sistema capitalista, defende o trabalho coletivo, o não acúmulo do capital e a produção associada (construção de redes de trabalhadores/as em trabalho associado). É diferente da Economia Popular, que se aproxima da economia informal, aparece como alternativa diante do desemprego e não se opõe ao mercado capitalista. Também se diferencia da Economia Solidária, haja vista que esta abarca diversas tipologias de empreendimentos - inclusive capitalistas - e tem vínculos com políticas públicas (IEPS/UEFS, 2012).

É com a Economia Popular e Solidária que a Incubadora de Iniciativas da Economia Popular e Solidária da Universidade Estadual de Feira de Santana - IEPS/UEFS trabalha e tem como base para atividades como a que será apresentada neste artigo.

Observa-se, na literatura, que no final do século XX e início do XXI, um aumento de experiências e de grupos no Brasil e no mundo, conhecido como Economia Popular e Solidária apontam alternativa ao desemprego e uma possível transformação social para a classe trabalhadora. No Brasil, é Paul Singer quem traz o conceito de Economia Solidária; ele foi, também, o primeiro secretário da Secretaria Nacional de Economia Solidária (SENAES) em 2003 e, a partir dessa institucionalização, o conceito de Economia Solidária passou a se 
relacionar com políticas públicas, sendo "adotada como diretriz estratégica para as ações de geração de trabalho e renda do governo federal” (NAGEM \& SILVA,2013, p.159)

\begin{abstract}
A economia solidária é outro modo de produção, cujos princípios básicos são a propriedade coletiva ou associada do capital e o direito à liberdade individual. A aplicação desses princípios une todos os que produzem numa única classe de trabalhadores que são possuidores de capital por igual em cada cooperativa ou sociedade econômica (SINGER, 2002, p.10).
\end{abstract}

Singer (2002), ao afirmar que a economia solidária é um modo de produção, analisa apenas a organização do trabalho, entretanto, essa característica por si só não define o modo de produção. Segundo Mangolin (2010), este é constituído por pelos menos três estruturas: a) a econômica; b) a jurídico-política e c) a ideológica; porém a estrutura econômica é a que determina o modo de produção. Diante do conceito de modo de produção, a economia solidária seria manifestações de outras formas de trabalhar e produzir, que está inserida em um modo de produção capitalista.

Razeto (1997) chama o conjunto de trabalhadores que desenvolvem a economia popular de economia dos setores populares e a esta atribui a característica de economia de solidariedade, pois "o trabalho é a atividade e principal meio pelo qual o ser humano desenvolve as suas potencialidades" (RAZETO, 1997, p.92).

Ao explicitar esse caráter de centralidade do trabalho como forma de humanização do ser humano, Razeto pretende restabelecer o papel central que o trabalho possui dentro da sociedade, contrapondo a relação que é posta pelo capitalismo em que o trabalho é sinônimo de emprego e reduz os sujeitos a meros fatores de produção.

Ao reduzir o trabalho a essa situação subalterna, o capitalismo impede que ele expresse sua riqueza de sentido e de conteúdo. Se o trabalho fica reduzido ao emprego, o ser humano que o realiza é apenas um empregado: um sujeito dependente, instrumental (RAZETO, 1997, p.92,93).

Portanto, para compreender essa outra economia é necessário entender que economia está para além do mercado autorregulado, como é o pressuposto da teoria neoclássica, é perceber a economia em várias dimensões e não apenas em única dimensão de troca. Reverter esse processo significa fortalecer os laços de solidariedade entre os/as trabalhadores/as que já vêm desenvolvendo experiências na geração de trabalho e renda de forma autônoma, seja 
individual ou coletiva, como forma alternativa ao desemprego ou mesmo como enfrentamento ao próprio modelo imposto pelo capital.

Esta economia popular solidária tem sido, e está sendo, capaz de suscitar um movimento de solidariedade, do qual participam pessoas e instituições, dispostas a colaborar com ela pela contribuição de recursos, ideias e trabalho (RAZETO, 1997, p.96).

A esse movimento endógeno (parte dos trabalhadores) que Razeto chama de economia popular solidária, e nessa construção solidária passa a caracterizar o popular. Essa economia é popular por que põe em cena as experiências de trabalhadores/as autogestionários/as diante do trabalho associado ou em cooperação.

\title{
A INCUBADORA DE INICIATIVAS DA ECONOMIA POPULAR E SOLIDÁRIA DA UNIVERSIDADE ESTADUAL DE FEIRA SANTANA - IEPS/UEFS
}

A Incubadora de Iniciativas da Economia Popular e Solidária - IEPS/UEFS é um projeto de pesquisa e programa de extensão interdisciplinar voltado para o desenvolvimento de outra organização de trabalho, numa perspectiva da Economia Popular e Solidária (EPS), tendo como objetivo: "Estimular a geração de trabalho e renda de iniciativas da economia popular e solidária visando a construção da autonomia dos sujeitos envolvidos no processo e sua inserção econômica e social” (IEPS/UEFS, 2012).

Na sua carta de princípios, a IEPS reafirma seu caráter permanente e seu compromisso com a extensão universitária:

\begin{abstract}
A Incubadora de Iniciativas da Economia Popular e Solidária da Universidade Estadual de Feira de Santana, IEPS-UEFS, constitui-se em um programa interdisciplinar de caráter permanente, desenvolvido por servidores, docentes e técnicos administrativos, e discentes da UEFS, com possibilidade de participação da comunidade externa, por meio de projetos de extensão e ou pesquisa e outras atividades de caráter continuado junto à comunidade externa, no âmbito da economia popular e solidária (IEPS/UEFS, 2011).
\end{abstract}

A proposta da IEPS/UEFS é acompanhar grupos produtivos urbanos ou rurais que desenvolve o seu trabalho de forma associativa ou cooperada e, dentro dessa lógica, ampliar o conceito de solidariedade a fim de construir uma economia popular e solidária. Para organizar o trabalho a IEPS divide-se em projetos em que estudantes, professores e técnicos desenvolvem os planos de ação. O Projeto Cantina Solidária foi o qual deu origem à 
incubadora, em 2008, com a proposta de ocupar uma das cantinas do próprio campus da Universidade, a fim de usar o espaço de forma pedagógica para desenvolver o trabalho com grupos de forma autogestionária.

Na forma de projetos, a IEPS-UEFS desenvolverá processos de incubação, os quais devem ser compreendidos como um processo político, práticoeducativo de organização e acompanhamento sistêmico a grupos envolvidos no processo econômico popular e solidário. Na incubação a IEPS-UEFS adotará os fundamentos da economia popular e solidária possibilitando a integração solidária dos sujeitos, colocando como valores principais o trabalho coletivo, o conhecimento e o atendimento às necessidades sociais da população (IEPS/UEFS, 2011).

Com base nesses princípios que a IEPS desenvolve as suas ações em duas cantinas da UEFS, uma no módulo I e a outra no módulo VII. Neste trabalho, vamos explicitar uma ação desenvolvida com o grupo produtivo que ocupa a cantina do módulo I e participa do Projeto Cantina Solidária III. Este grupo é formado por 12 mulheres da Comunidade Quilombola da Lagoa Grande, na cidade de Feira de Santana - Bahia, em processo de incubação desde junho de 2016, denominado Sabores do Quilombo.

\section{O QUE AS TRABALHADORAS TÊM A DIZER?}

Diante do estímulo "O que é Economia Popular e Solidária?”, foram trazidas pelas mulheres do grupo incubado pelo Projeto Cantina III as palavras União, Paciência, Desenvolvimento, Igualdade, Verdadeiro, Harmonia, Coletividade, Fortalecimento, Trabalho, Coletividade e Solidariedade, que junto com as explicações resultaram no seguinte quadro:

QUADRO 1- RESPOSTAS E EXPLICAÇÃO DAS MULHERES À PERGUNTA

\begin{tabular}{|l|l|l|}
\hline $\begin{array}{l}\text { RESPOSTAS DAS } \\
\text { MULHERES }\end{array}$ & $\begin{array}{l}\text { EXPLICAÇÃO } \\
\text { INDIVIDUAL }\end{array}$ & $\begin{array}{l}\text { EXPLICAÇÃO } \\
\text { COLETIVA }\end{array}$ \\
\hline União & $\begin{array}{l}\text { Necessário para fazer a } \\
\text { diferença. }\end{array}$ & $\begin{array}{l}\text { É o centro para os bons } \\
\text { relacionamentos. }\end{array}$ \\
\hline Paciência & $\begin{array}{l}\text { A Economia Popular e } \\
\text { Solidária é andar para } \\
\text { frente; } \\
\text { Crescer, multiplicar e } \\
\text { misturar as forças. }\end{array}$ & \\
\hline Desenvolvimento & \multicolumn{2}{|l}{} \\
\hline
\end{tabular}




\begin{tabular}{|c|c|c|}
\hline Igualdade & $\begin{array}{l}\text { Dentro da Economia } \\
\text { Popular e Solidária tem que } \\
\text { haver igualdade para todos }\end{array}$ & $\begin{array}{l}\text { Não ter superioridades } \\
\text { mesmo com ideias diferentes } \\
\text { para chegar em um consenso }\end{array}$ \\
\hline Verdadeiro & $\begin{array}{l}\text { Necessário para existir } \\
\text { união. }\end{array}$ & $\begin{array}{l}\text { Coletivização das } \\
\text { informações. }\end{array}$ \\
\hline Harmonia & $\begin{array}{l}\text { Necessário para trabalhar } \\
\text { coletivamente. }\end{array}$ & $\begin{array}{l}\text { Estar bem consigo mesmo e } \\
\text { com o outro. }\end{array}$ \\
\hline Coletividade & $\begin{array}{l}\text { Junto com a união, contribui } \\
\text { para o desenvolvimento da } \\
\text { Economia Popular } \\
\text { Solidária. }\end{array}$ & $\begin{array}{l}\text { Estar junto em tudo para } \\
\text { crescer; Doação. }\end{array}$ \\
\hline Fortalecimento & $\begin{array}{l}\text { A Economia Popular e } \\
\text { Solidária fortalece o } \\
\text { desenvolvimento local } \\
\text { através da coletividade; } \\
\text { Juntar tudo de bom } \\
\text { (coragem, paz, bondade, } \\
\text { alegria). }\end{array}$ & $\begin{array}{l}\text { Resolver dificuldades de } \\
\text { maneira positiva. }\end{array}$ \\
\hline Trabalho & $\begin{array}{l}\text { A Economia Popular e } \\
\text { Solidária contribui para o } \\
\text { desenvolvimento } \\
\text { trabalho em vários espaços } \\
\text { não só na cantina. }\end{array}$ & $\begin{array}{l}\text { (Trabalho = doação, hábito } \\
\text { que aparece constantemente } \\
\text { em casa). }\end{array}$ \\
\hline Compreensão & $\begin{array}{l}\text { A solidariedade (sozinho } \\
\text { não consegue fazer nada) } \\
\text { exige compreensão }\end{array}$ & $\begin{array}{l}\text { Deve aparecer nas pequenas } \\
\text { coisas; } \\
\text { Entender } \\
\text { Participação } \\
\text { formações). }\end{array}$ \\
\hline Solidariedade & $\begin{array}{l}\text { Precisa existir independente } \\
\text { de qualquer coisa }\end{array}$ & Mesmo diante de conflitos \\
\hline
\end{tabular}

Elaboração própria, 2017.

Durante as reflexões, a pessoa que disse a palavra "Desenvolvimento" teve dificuldade em dizer a relação deste termo com a Economia Popular e Solidária, assim como definir a palavra apresentada, desejando por um momento ir embora da oficina e esperando que nós, integrantes da IEPS/UEFS, respondêssemos por ela. Depois de um tempo, disse que "Desenvolvimento é andar para frente" (sic). Outra integrante afirmou, no final, ainda, que a atividade fez com que ela percebesse que sabe, mas não tinha noção ainda.

As explanações dos termos Verdadeiros", "Paciência" e "Harmonia" foram utilizadas 
para indicar onde há falhas internas. Durante as discussões coletivas, isso ficou mais evidente. O debate sobre Economia Popular e Solidária foi substituído pelas questões que geram conflitos interpessoais no grupo, onde uma colocava o defeito como de outra pessoa, sem se implicar no problema, sem dizer como contribui para o conflito. Ao final, isso resultou numa reflexão sobre o que cada uma trazia em si que poderia atrapalhar o grupo e três pessoas chegaram a compartilhar com o grupo o que reconheceu ser necessário ser trabalhado: uma disse que precisava ter mais paciência; outra compreensão, e outra reconheceu que precisava dar espaço para as demais se manifestarem.

Uma participante disse que "união era necessário para fazer a diferença" e o grupo foi questionado que diferença era essa, do que a Economia Popular e Solidária queria se diferenciar, e outra pessoa disse que a EPS surge para se diferenciar da Economia Tradicional e que esta parece ser boa até conhecer a Economia Popular e Solidária. Ela acrescentou ainda que o trabalho com EPS mudou tudo na sua vida; falou que é diferente por ser patroa, e após ser questionada sobre este cargo dentro da EPS, ela disse que se tornou patroa de si mesma. Duas integrantes do grupo, ainda, afirmaram que já buscaram informações sobre a EPS além do que é apresentado pela IEPS/UEFS na internet.

\section{CONHECIMENTOS COMPARTILHADOS: O SABER CIENTÍFICO E O POPULAR}

É perceptível, por meio das oficinas e observações diárias, que o grupo ainda demanda trabalhos voltados para mediação de conflitos e relações grupais, haja vista que há uma busca por uma harmonia como se um contexto favorável fosse aquele em que não há conflitos, e muitos dos problemas do espaço da cantina são colocados como pessoal. Lane (1996) aponta que o grupo é condição para a consciência (autorreflexão a partir do conhecimento de uma realidade comum) e para a atividade (ação conjunta e organizada). As relações sociais "se desenvolvem através de atividades que, por sua vez, sofrem a mediação de emoções individuais" (LANE, 1996, p.31), ou seja, é através das relações grupais que a pessoa manifesta conteúdos afetivos, que pode realizar o processo de autorreflexão e de ação conjunta; isso foi o que este trabalho proporcionou ao grupo Sabores do Quilombo de maneira pontual e com implicação das pessoas envolvidas, através da discussão sobre Economia Popular e Solidária e relações interpessoais dentro da cantina.

Observa-se, também, um equívoco quanto à ideia de autogestão por uma das mulheres quando se diz "patroa de si mesma", entretanto, essa confusão ocorre também no meio acadêmico nas discussões sobre empreendedorismo e trabalho social ou voluntário. 
Patrão não faz parte da lógica autogestionária, pois nesta todos/as os/as trabalhadores/as “detém posses iguais, com os mesmos direitos de decisão sobre seu destino [...] participando plenamente dos resultados alcançados" (CASTANHEIRA \& PEREIRA, 2008, p.117). Mas fica a dúvida se ela quis dizer que adquiriu uma autonomia ou se quis dizer que é patroa, dona, numa perspectiva individual e não coletiva - como é na autogestão.

Apesar de dificuldades para explicar conceitos da Economia Popular e Solidária, o grupo entende e consegue usar suas próprias palavras para definir os termos já apresentados em espaços formativos realizados pela IEPS/UEFS e que esta dificuldade surge da vontade de agradar a IEPS/UEFS e não pelo desconhecimento sobre os temas, como pode ser percebido através da palavra "Desenvolvimento". Este termo é muito utilizado pela IEPS/UEFS, a trabalhadora trouxe para o quadro, mas achou que não sabia o que significava. Ainda assim, diante da dúvida e incerteza, ela chegou à conclusão que estava querendo dizer "andar para frente", deixando seu saber popular aparecer, sua forma de explicar as coisas. Isso se relaciona com a importância do Popular na Economia Popular e Solidária, o que Razeto aponta como "[...] a chegada de uma força que em definitivo constitui-se na mais poderosa das forças: a solidariedade que liberta, criando vínculos de organização e de comunidade" (RAZETO, 1997, p.94).

\section{CONSIDERAÇÕES FINAIS}

Esta atividade contribuiu para uma reflexão sobre a outra economia trabalhada no processo de incubação. Foi percebido que, apesar de dificuldades para explicar conceitos da Economia Popular e Solidária, o grupo entende e consegue usar suas próprias palavras para definir os termos já apresentados em espaços formativos realizados pela IEPS, que a ideia de patrão ainda está presente no grupo e que houve diálogo do saber popular com conhecimento científico. E esse processo de incubação caminha de maneira positiva, já que as representações sociais que surgiram não se opõem à proposta metodológica e política da incubadora.

Diante disso, entendemos que o grupo psicoeducativo garantiu uma reflexão a partir das representações sociais e conhecimentos cotidianos compartilhados. Entretanto, o grupo demanda formações sobre trabalho associado e mediação de conflitos.

THE POPULAR AND SOLIDARITY ECONOMY UNDER THE SOCIAL 


\title{
REPRESENTATION OF WORKING WOMEN OF THE COMMUNITY QUILOMBOLA DE LAGOA GRANDE - FEIRA DE SANTANA - BA
}

\begin{abstract}
:
This work was subject to a research carried out with the group of producers of the Incubator of Popular and Solidarity Economy of the State University of Feira de Santana - IEPS / UEFS. Having as objectives: to identify the social representations of the group Sabores do Quilombo on the Popular and Solidary Economy; analysis of the incubation process and; identify the formative demands of the group for the Incubator. The researches were done over time, in order to popularize and discuss about conflicts and relationships, through a psychoeducational group. As results of the research, although partial, because the process is in progress, we infer that the workers develop in an organic way elements of the popular and solidarity economy although they are not fixed or on their conceptual domains.
\end{abstract}

Keywords: Popular and solidarity economy. Working women quilombolas. Social representations.

\section{REFERÊNCIAS}

Carta de Princípios. Feira de Santana, BA, 2011.

BAZON, M.R. Psico-educação: um projeto visando aumentar a eficiência das intervenções sociais junto às crianças e adolescentes em situação de risco psico-social em Ribeirão Preto. Revista Padéia. Ribeirão Preto: FFCLRP - USP. 1997.

BORDA, Orlando Fals. Aspectos teóricos da pesquisa participante: considerações sobre o significado e o papel da ciência na participação popular. In: Carlos Rodrigues Brandão. Pesquisa Participante. 3 ed. São Paulo: Brasiliense,1983. p.42-62.

FREIRE, Paulo. Criando métodos de pesquisa alternativa: aprendendo a faze-la melhor através da ação. In: Carlos Rodrigues Brandão. Pesquisa Participante. 3 ed. São Paulo: Brasiliense,1983. p.34-41.

INCUBADORA DE INICIATIVAS DA ECONOMIA POPULAR E SOLIDÁRIA DA UNIVERSIDADE ESTADUAL DE FEIRA DE SANTANA - IEPS/UEFS. Programa Incubadora. Feira de Santana, BA, 2012.

JOVCHELOVITCH, Sandra. Os contextos do saber: representações, +comunidade e cultura. Tradução de Pedrinho Guareschi. Petrópolis: Vozes. 2008, p. 78-126.

LANE, S. Histórico e fundamentos da psicologia comunitária no Brasil. In R.H. F. Campos (org), Psicologia Comunitária: da solidariedade à autonomia. Petrópolis: Vozes. 1996, p. 17-34.

MANGOLIN, B. Cesar. O conceito de modo de produção. 2010. Disponível em:<https://moodle.ufsc.br/pluginfile.php/934137/mod_resource/content/1/elementos básicos0_MODO_DE_PRODUÇÃO.pdf>. Acesso em: 15 jun. 2018.

MOURA, Clóvis. Os Quilombos e a Rebelião Negra. São Paulo: Brasiliense. Ed 5. 1987, p. 34-43. 
MOURA, L.S. e LIMA, J.R.O. Tecnologia Social: a experiência de atividades Administrativas desenvolvidas Junto ao Programa Incubadora de Iniciativas da Economia Popular e Solidária da Universidade Estadual de Feira de Santana - Bahia (PIEPS/UEFS). 2015, p. 3, no prelo.

NAGEM, F.A. \& SILVA, S.P. Institucionalização e Execução das Políticas Públicas de Economia Popular e Solidária no Brasil. Revista de Sociologia e Política. v.21, na 46. Curitiba. jun/2013.

PEREIRA, J.R. \& CASTANHEIRA, M.E.M. Ação coletiva no âmbito da economia solidária e da autogestão. RevistaKatálysis Minas Gerais, v.11, n.1. 2008.

RAZETO, M. Luis. O Papel Central do Trabalho e a Economia de Solidariedade. Revista Proposta: FASE, Rio de Janeiro, v. 75, n. 26, p.91-99, dez/fev. 1997/98. Trimestral.

SINGER, Paul. Introdução à Economia Solidária. 1 ed. São Paulo: Perseu Abramo, 2002. 